Article

\title{
Fuzzy Preference Programming Framework for Functional Assessment of Subway Networks
}

\author{
Mona Abouhamad ${ }^{1, *(1)}$ and Tarek Zayed ${ }^{2}$ (I) \\ 1 Construction Management, Structural Engineering Department, Faculty of Engineering, Cairo University, \\ Cairo University Rd., Giza 12613, Egypt \\ 2 Department of Building and Real Estate, Hong Kong Polytechnic University, Hong Kong, China; \\ tarek.zayed@polyu.edu.hk \\ * Correspondence: m.abouhamad@eng.cu.edu.eg; Tel.: +2-010-931-59789
}

Received: 11 August 2020; Accepted: 28 August 2020; Published: 3 September 2020

\begin{abstract}
The 2019 Canadian Infrastructure report card identified $60 \%$ of the subway system to be in a very poor to a poor condition. With multiple assets competing for the limited fund, new methodologies are required to prioritize assets for rehabilitation. The report suggested that adopting an Asset Management Plan would assist municipalities in maintaining and operating infrastructure effectively. ISO 55000 emphasized the importance of risk assessment in assessing the value of an organization's assets. Subway risk assessment models mainly focus on structural failures with minimum focus on functional failure impacts and network criticality attributes. This research presents two modules to measure the functional failure impacts of a subway network, given financial, social, and operational perspectives, in addition to the station criticality. The model uses the Fuzzy Analytical Network Process with application to Fuzzy Preference Programming to calculate the weights for seven failure impact attributers and seven criticality attributes. Data are collected using questionnaires and unstructured/structured interviews with municipality personnel. The analysis identified social impacts to have the highest score of $38 \%$, followed by operational and financial impacts at $34 \%$ and $27.65 \%$, respectively. The subway station criticality revealed station location to have the highest impact at $35 \%$, followed by station nature of use and station characteristics at $30.5 \%$ and $31.82 \%$, respectively. When integrated with probability of failure, this model provides a comprehensive risk index to optimize stations for rehabilitation.
\end{abstract}

Keywords: fuzzy ANP; fuzzy preference programming; subway network; impacts of failure; infrastructure assets; criticality index

\section{Introduction}

The 2019 Canadian Infrastructure report card identified $60 \%$ of the subway system to be in a very poor to a poor condition. The report specified $16 \%$ of the subway system to be in a very poor condition being near or beyond its service life and showing advanced signs of deterioration. The remaining $44 \%$ were identified to be in a poor condition where the infrastructure condition is below the expected standard and a large portion of the system suffering from significant deterioration [1]. The report card recommended that municipalities adopt an asset management plan to understand the state of their infrastructure assets and, accordingly, plan the lifecycle expenditures. Risk assessment is an integral part of a comprehensive risk management plan [2]. Risk combines the probability of an asset failure with the expected failure impacts to provide an informed view of the asset under study. Probability of failure is usually assessed using deterioration curves for the studied element, whereas failure impacts are more difficult to assess with tangible and intangible impacts along multiple perspectives. The literature on failure impacts estimation in subway networks are scarce, with only handful of 
researchers approaching the topic. This research addresses the functional failure impacts of subway networks from three dimensions: financial, social, and, operational. The Fuzzy Analytical Network Process is utilized to capture the interdependencies of the impacts assessed and their intangible nature. Stations criticality is also assessed to indicate the importance of each station within the network it operates.

\section{Background}

Subway assessment efforts in the literature mainly focus on structural assessment models. [3] developed a structural assessment model to assess the structural performance of the subway systems elements. [4] developed a subway physical vulnerability framework based on network theory and Failure Modes, Effects, and Criticality analysis. [5] developed a condition assessment model for subway systems considering structural, electrical, and mechanical components. [6] developed a risk-based asset management framework for subway systems. [7] developed a deterioration mapping model in subway infrastructure using sensory data of Ground Penetrating Radar (GPR).

On the contrary, the subway area is very scarce in failure impact estimation models, unlike the sewer and pipelines domain. Sewers and pipelines had the largest share of literature dedicated to estimating consequence of failure. The United Kingdom's Water Research Center (WRC) [8] assessed failure impacts considering socioeconomic and reconstruction impacts. Socioeconomic impacts included the threat to human health and environmental quality, and costs associated with loss of commerce, critical services, and sewer service. However, the reconstruction impacts estimated the repair/replacement costs of failed sewers. [9] developed a knowledge-based expert system to predict the impacts of failure based on the WRC 1986 paradigm of assessing the pipes. [10] developed a fuzzy qualitative risk model for buried pipelines. [11] developed an individual pipe level risk assessment model considering geographical, physical, and functional attributes of sewer pipes in light of expert opinions. [12] developed a risk model for water main failure, where failure impacts included the repair cost, traffic and business disruption, loss of production, and type of service area. Seattle Public Utilities estimated failure impacts as the multiplication of base repair/replacement cost with modification factors based on the attributes of sewer pipes [13].

Reference [14] applied the Reliability Centered Maintenance methodology in railway infrastructures. They assessed the criticality of a system as the measure of functional importance of the system and computed criticality in terms of the technology utilized, traffic density, exploitation revenues, line availability, and safety and environmental risk. [15] ranked machines and classified them according to their importance for the entire railway network based on their criticality score. The City of Edmonton applied a "severity" indicator to provide an analysis of assets in critical condition and the failure impact of those assets [16]. The different methods to compute criticality or severity basically reflect the importance of the components of a system in terms of functionality and importance in delivering the final service or product. In their risk-based asset management model, [6] used a criticality index to identify the relative importance of each station in a network model.

A formal review of the failure impacts and specific importance of a sub-system element diverts attention to cost effective maintenance tasks. This ensures an optimized maintenance spending and a guaranteed equipment reliability [15]. Failure impacts measure the various tangible types of loss, including repair cost, property damage, and revenue loss. Nevertheless, intangible expected impacts such as loss of reliability, disruption of service, and different social impacts represent criticality factors that should be used to further prioritize stations.

\section{The Fuzzy Analytic Network Process}

In real-life decision-making situations, decision makers or experts could be uncertain about their own level of preference, due to incomplete information, insufficient knowledge, complexity, lack of appropriate measurement scale, or uncertainty within the decision environment. Decision makers also tend to specify preferences in the form of natural language expressions, which are most often vague 
and uncertain [17]. Fuzzy logic is a natural way to incorporate the uncertainty or the vagueness of the human judgment. When comparing two elements, the uncertain numerical ratio is expressed in a fuzzy manner rather than an exact one. Then, an appropriate prioritization procedure is applied to derive local priorities approximately satisfying the provided judgments.

The concept of Fuzzy Analytical Hierarchy Process (FAHP) and Fuzzy Analytical Network Process (FANP) was extensively researched in literature and several fuzzy models were introduced. The common methods used for prioritization include, Saaty's original Eigen Vector method, The Direct Least Squares Method proposed by [18], Logarithmic Least Squares Method also known as the geometric method [19], goal programming method proposed by [20], and Fuzzy Preference Programming Method proposed by [21].

Fuzzy Preference Programming (FPP) adopts the concept of $\alpha$-cuts to decompose fuzzy numbers into a number of intervals in order to represent the initial fuzzy sets. The method calculates priorities for each $\alpha$-level cut that are further aggregated into crisp local and global priorities [22]. The FPP method is based on two assumptions: The first assumption requires the existence of nonempty fuzzy feasible area $\widetilde{P}$ on the simplex hyper plane $Q^{n-1}$, as shown in Equation (1) $Q^{n-1}$,

$$
Q^{n-1}=\left\{\left(w_{1} \ldots w_{\mathrm{n}}\right) \mid w_{\mathrm{i}}>0, \sum_{i=1}^{n} w_{i}=1\right\} .
$$

The membership function of the fuzzy feasible area is expressed in terms of the intersection of all interval membership functions in $\mu_{k}\left(R_{k} w\right)$, as shown in Equation (2):

$$
\mu_{\widetilde{P}}(\mathrm{w})=\left[\min \left\{\mu_{1}(R 1 w), \mu_{m}(R m w)\right\} \mid w \in Q^{n-1}\right]
$$

The second assumption: specifies a selection rule, which determines a priority vector having the highest degree of membership in the aggregated membership function $\mu_{p}(w)$, since $\widetilde{P}$ is a convex set, then there is always a priority vector $(w)$ in $Q^{n-1}$ that has a maximum degree of membership $(\lambda)$; therefore, Equation (3) can be concluded:

$$
\mu_{\widetilde{P}}(w)=\lambda=\max \left[\min \left\{\mu_{1}\left(R_{1} w\right) \ldots \mu_{m}\left(R_{m} w\right)\right\} \mid w \in Q^{n-1}\right]
$$

The max-min prioritization problem can be represented as the fuzzy programming problem shown in Equation (4):

\section{$\operatorname{Max} \lambda$}

$$
\begin{aligned}
& \text { Subject to } d_{k} \lambda+R_{k} w \leq d_{K} \quad k=1,2 \ldots m \quad m=n(n-1) / 2 \text {. } \\
& \sum_{i=1}^{n} w_{i}=1, \quad w_{i}>0, \quad i=1,2,3 \ldots n
\end{aligned}
$$

The optimal solution to this problem $\left(w^{*}, \lambda^{*}\right)$ is a vector whose first component represents the priority vector that maximizes the degree of membership in the fuzzy feasible area, whereas its second component gives the value of that maximum degree $\mu_{p}\left(w^{*}\right)=\lambda^{*}$ is the consistency index which measures the degree of satisfaction and is a natural indicator for the inconsistency of the decision-makers' judgments. $\lambda^{*}$ takes a value greater than or equal one when the human interval judgments are consistent, whereas for inconsistent judgments the consistency index $\left(\lambda^{*}\right)$ takes a value between 0 and 1 depending upon the degree of inconsistency and the values of the tolerance parameters $d_{K}$ [21]. It can be concluded that FPP transforms the prioritization problem into a linear program that can easily be solved by standard simplex technique. It should be noted when applying this method that all tolerance parameters can be set equal since the decision-makers usually have no preferences about their specific pairwise comparison judgments. In addition, the values of the tolerance parameters, if equal, do not affect the value of the maximizing solution $w^{*}$. 
Reference [22] also developed a non-linear fuzzy prioritization model to obtain directly crisp values of priorities from a set of comparison judgments, represented as triangular fuzzy numbers. If the optimal value of $\lambda^{*}$ is positive, this indicates all solution ratios satisfy the fuzzy judgment completely, which means that the initial set of fuzzy judgments is rather consistent. Alternatively, a negative value of $\left(\lambda^{*}\right)$ shows the solution ratios approximately satisfy all double-side inequalities. Therefore, the optimal value $\lambda^{*}$ can be used for measuring the consistency of the initial set of fuzzy judgments.

FANP handles the uncertainty in quite a different manner than that of regular ANP with sensitivity analysis. Fuzzy ANP accommodates the subjectivity of human judgment as being expressed in natural language which entails 'fuzziness' in real-life problems. It should be clear, however, that an obvious difference exists between 'fuzziness' in human judgment within the ANP and the inconsistency in judgment. The inconsistency in judgments is measured by the consistency ratio (CR) proposed by Saaty [23], to test the reliability of the decision outcomes. Higher values of CR imply that inconsistency occurs because of some "errors in judgment" on the part of the expert. Some of the causes of inconsistency may be lack of information, lack of concentration during judgment process, and inadequate model structure. The process of applying Fuzzy ANP using FPP can be summarized in the following main steps:

1. Decompose the decision problem to construct a network structure including clusters, criteria, attributes and, alternatives;

2. Highlight dependences among all components and define the impact between each,

3. Construct pairwise comparison matrices of components with crisp, interval, or, fuzzy ratio judgments;

4. Perform FPP on each comparison matrix to derive each set of local priorities;

5. Form an unweighted supermatrix with the derived local priorities;

6. Produce the weighted supermatrix by adjusting the supermatrix to column stochastic;

7. Find the limit supermatrix with a sufficiently large power number to converge into a stable supermatrix;

8. Obtain the final priorities via aggregating weights of criteria and scores of alternatives.

\section{Methodology and Implementation}

This research presents the failure impacts module and criticality index module developed for subway systems. Both modules work on identifying a failure impact index and a criticality index on an element level, and then, using a system modeling technique, aggregate the indices to the stations, lines, and network level. The two modules can be integrated with a probability of failure module to obtain a comprehensive risk index as can be seen in [6]. Nevertheless, the modules can be observed as stand-alone modules for functional assessment of failure impacts and criticality level of a subway network/component. Failure impacts address the financial, social, and operational impacts expected in case of occurrence of operational failure. The criticality index tackles the individual station importance arising from its geographical location in proximity to important location and expected ridership.

\subsection{Failure Impacts Module}

Determining failure impacts presents a challenging problem to researchers and industry experts due to the uncertainties associated with the different financial, social, and operational aspects of the impacts. While direct financial impacts of a subway failure can be estimated based on historical data, calculating failure impacts for intangible factors, such as social, economic, and even indirect cost of failure in monetary terms is difficult and does not yield accurate results due to the high level of uncertainty and subjectivity associated with these factors.

Indirect impacts of failure in subway stations include numerous attributes such as service disruption, delay of passengers, reputation loss, and revenue deficit, in addition to other socio-economic impacts. Therefore, determining failure impacts is crucial because it provides public authorities with 
a framework for clustering network components based on their relative importance. The triple bottom line approach is used to determine failure impacts on a multi-perspective level. A station is composed of a number of elements operating simultaneously. Based on the location of the element and its nature, the element failure might cause total, partial, or no station closure. This suggests failure impacts are element-dependent, hence, the failure impacts module is developed on elements level and aggregated upwards to the stations and network levels of a subway hierarchy using the parallel-series network modeling approach. Based on literature review and expert feedback, failure impacts were grouped into financial, social, and, operational impacts. It is noted that some factors are independent and follow two different perspectives simultaneously. Figure 1 demonstrates the main criteria and attributes considered in the failure impacts module. Financial impacts of failure represent the direct tangible impacts measured in terms of cost of maintenance, repair, or replacement of the failed component(s). This is in addition to the expected revenue loss due to partial or total station failure or service interruption. Operational impacts are those involving managerial decisions, such as time to repair and ease of providing alternative. Social impacts are the direct social failure impacts incurred by the customers. They are measured in terms of the user traffic frequency, interruption rate, and service continuation. The magnitude of the social impacts is directly proportional to the number of users using this station and the adjacent businesses to which the station connects.

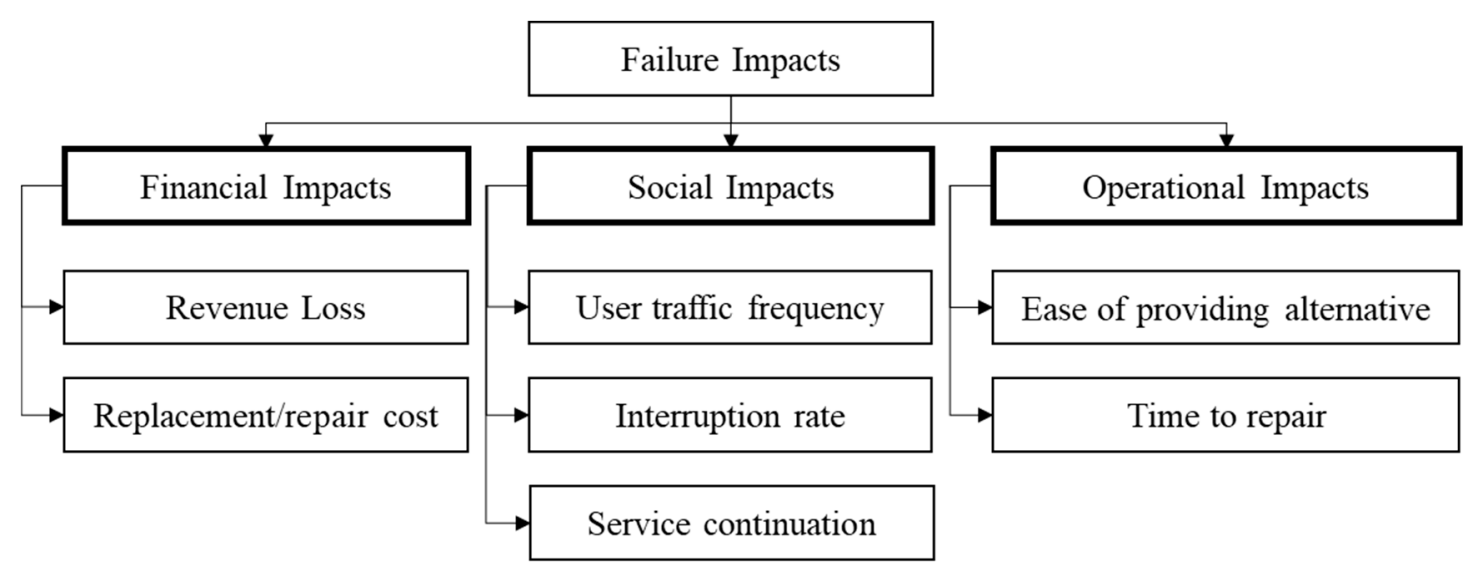

Figure 1. Failure impacts Attributes [6].

Examining failure impacts revealed a level of interdependency between attributes and sub-attributes. This is the type of interdependency precisely modeled by ANP. Furthermore, these attributes convey a degree of fuzziness and subjectivity derived from using experts' opinion; thus, the FANP will be utilized to develop the model. FANP addresses the interdependency inherent in the relation between these factors; in addition, it accounts for the uncertainty caused by the use of expert opinions due to the topic subjectivity.

Failure impacts considered in this research are quite diverse; therefore, they were measured using indices to facilitate the comparison between the expected impacts and to highlight the areas of higher impact. FANP with application to FPP was used as the main analysis tool to obtain the failure impacts criteria weights. The membership function maps crisp inputs in the universe of discourse to degrees of membership within a certain interval, which is usually $[0,1]$. Then, the degree of membership specifies the extent to which a given element belongs to a set or is related to a concept. A fuzzy extension of the five-point fundamental scale proposed by Saaty will be used in the pairwise comparison process. Triangular fuzzy numbers were selected for their wide applicability and ease of comprehension by decision makers. A fuzzy scale of $\widetilde{1}$ to $\widetilde{9}$ will be used to represent subjective pairwise comparison of the selection process in order to capture the vagueness of the comparison. The scale and its reciprocal are shown in Table 1. 
Table 1. Linguistic Scale of Relative Importance.

\begin{tabular}{ccc}
\hline Linguistic Scale Used & Triangular Fuzzy Scale & Triangular Fuzzy Reciprocal Scale \\
\hline Equal Importance & $(1,1,1)$ & $(1,1,1)$ \\
Moderate & $(2,3,4)$ & $(1 / 4,1 / 3,1 / 2)$ \\
Strong & $(4,5,6)$ & $(1 / 6,1 / 5,1 / 4)$ \\
Very Strong & $(6,7,8)$ & $(1 / 8,1 / 7,1 / 6)$ \\
Absolute & $(9,9,9)$ & $(1 / 9,1 / 9,1 / 9)$ \\
\hline
\end{tabular}

Following the FANP calculation scheme, the failure impacts estimation module is structured as a network of clusters and nodes. The objective is to determine the relative weight for the different impacts of failure through considering what affects failure impacts in a subway station and introduce them as clusters, nodes, and influence links in a network. The clusters include financial, operational, and social impacts of failure.

The financial impacts cluster includes maintenance and rehabilitation cost and revenue loss. The operational impacts cluster includes time to repair and ease of providing alternative. The social impacts of failure cluster include user traffic frequency, degree of service continuation (total/partial/none), and interruption rate. The linked nodes in a given cluster are pairwise compared to determine the priority of their influence on the parent node. Comparisons are conducted to measure the extent to which a node is more important in capturing failure impacts. These priorities are then entered in the supermatrix for the network. The clusters are also pairwise compared to establish their importance with respect to each other. The resulting matrix of numbers is used to weight the corresponding blocks of the original unweighted supermatrix to obtain the weighted supermatrix and consequently the limit matrix. Failure impacts are measured on a relative scale against predetermined attributes to capture the multi-perspective impacts of failure. The factors' weight, as well as the station evaluation in terms of these impacts, was conducted qualitatively in light of expert feedback. In addition, the factors selected, and their credibility was refined through checking with experts and improving the selected impacts accordingly.

The failure impacts module follows three main steps to calculate the CoF score per subway element. Sample screenshot for the calculation sheet is shown in Figure 2. In the financial impacts cluster, the expected revenue loss is identified per element and then normalized based upon the maximum value available for the network under study. Repair cost score is calculated based upon the repair option selected and normalized to the maximum score which is the replacement option. These steps are repeated for the social and operational impacts of failure. Using the weights obtained from FANP calculations, the impact value per element is calculated as seen in the last highlighted column (CoF).

\subsubsection{Calculate Failure Impacts Weights $\left(\mathrm{IW}_{\mathrm{i}}\right)$}

This step includes extracting data from questionnaires to use as input in the FANP model. A total of 107 questionnaires were sent from which 33 replies were received, with a response rate of $31 \%$. The received questionnaires were examined thoroughly. Accordingly, 17 surveys were totally disqualified due to missing/unrealistic replies. The questionnaire was distributed by hand to Transit Authority experts during meetings and interviews. The online survey link was communicated to transit groups on business-oriented social networking services websites; in addition, it was sent by email to subway and transit systems personnel. Experts' feedback was extracted manually in case of hard copy and email questionnaires and extracted automatically in case of online questionnaires to a MS Excel ${ }^{\circledR}$ worksheet. Once all data were assembled correctly in the work sheet, this file was imported into MATLAB ${ }^{\circledR}$, where the FANP code was written. This step resulted in the global weights for impact criteria and the local and global weights for attributes as presented in Table 2. 


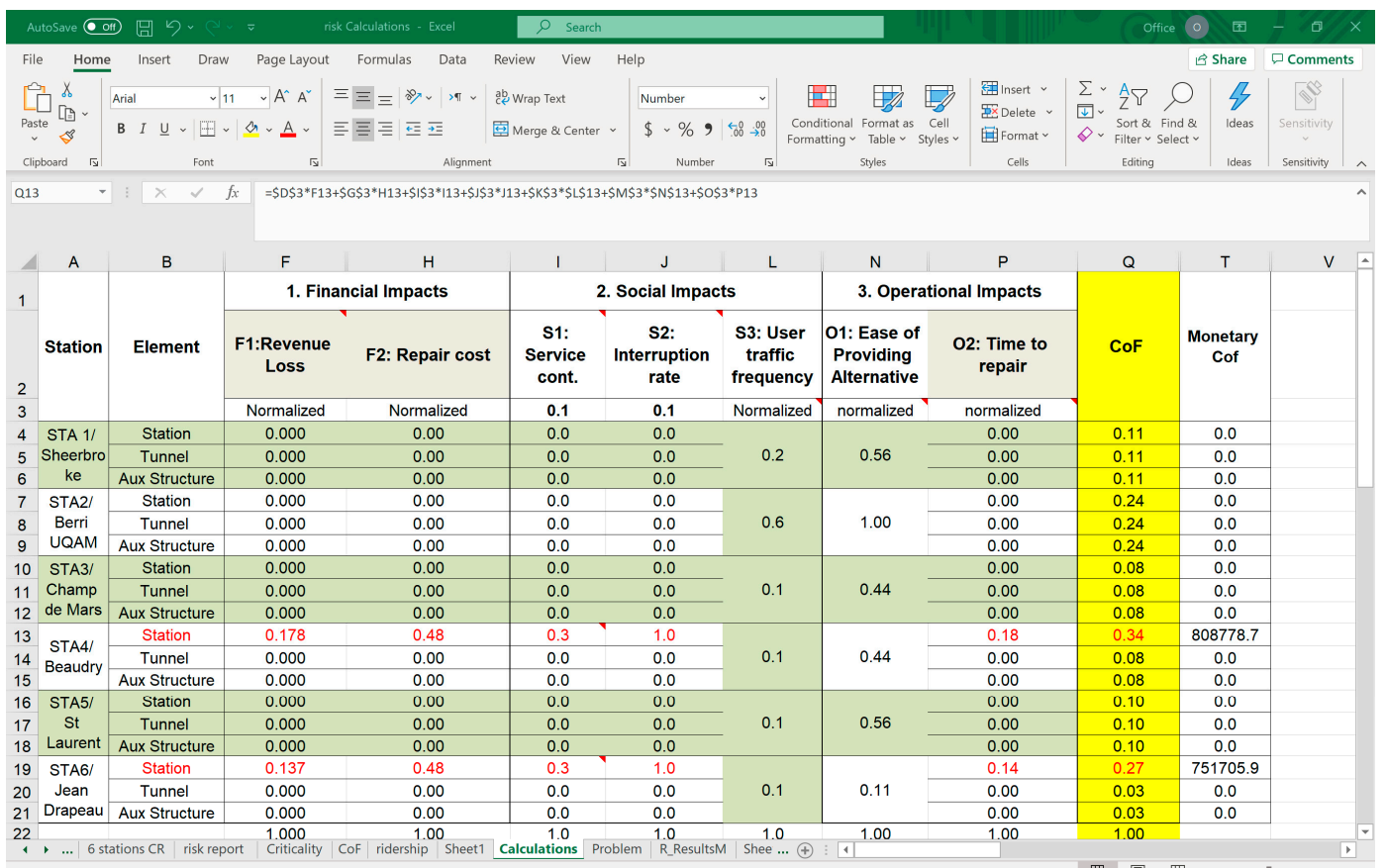

Figure 2. Failure impacts Calculation Sheet.

Table 2. Local and Global Weights of Failure impacts Module.

\begin{tabular}{|c|c|c|c|c|}
\hline Main Criteria & Global Weight & Attributes & Global Weight & Local Weight \\
\hline \multirow{2}{*}{ Financial Impacts } & \multirow{2}{*}{$27.65 \%$} & F1:Revenue Loss & $14.96 \%$ & $54.12 \%$ \\
\hline & & F2: Replacement/repair cost & $12.68 \%$ & $45.87 \%$ \\
\hline \multirow{3}{*}{ Social Impacts } & \multirow{3}{*}{$38.21 \%$} & S1: Service continuation & $12.95 \%$ & $33.90 \%$ \\
\hline & & S2: Interruption rate & $10.22 \%$ & $26.73 \%$ \\
\hline & & S3: User traffic frequency & $15.04 \%$ & $39.36 \%$ \\
\hline \multirow{2}{*}{ Operational Impacts } & \multirow{2}{*}{$34.14 \%$} & O1: Ease of Providing Alt. & $15.69 \%$ & $45.96 \%$ \\
\hline & & O2: Time to repair & $18.45 \%$ & $54.04 \%$ \\
\hline
\end{tabular}

\subsubsection{Model Testing}

The local and global weights presented in Table 2 and illustrated graphically in Figure 3 were tested using expert judgment. Accordingly, the model was presented and approved by the Transportation agency personnel in charge of the network's risk assessment. They verified the model output was legitimate and adequately conveys the network studied.

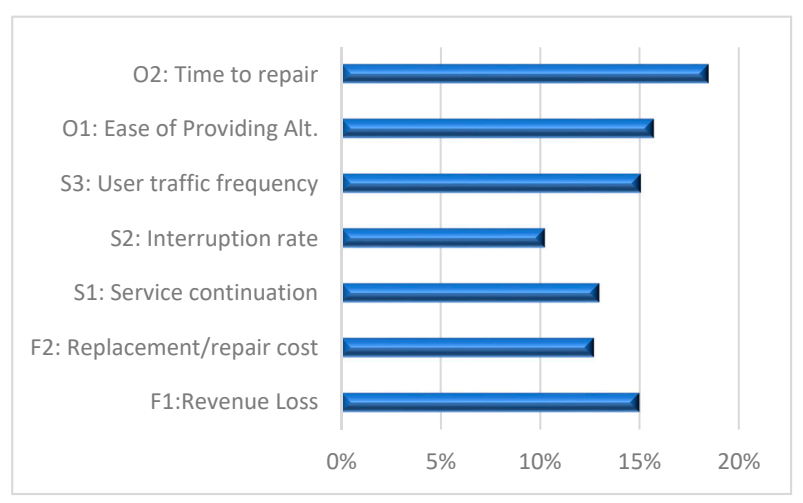

Figure 3. Failure impacts attributes Global Weights. 
The social impacts of failure had the highest importance, with a value of $38 \%$, followed by operational impacts at $34 \%$, and lastly, financial impacts at $27.65 \%$. These values conform to the current approach followed by the transportation agency for the network under study, where stations with higher effect on customers acquire a higher priority for rehabilitation to ensure customer satisfaction. Moreover, the membership functions implications provided by experts stated that financial impacts are usually covered by operational costs for moderate and low consequence of failure.

Attributes and criteria weights are shown graphically in Figures 3 and 4, time to repair had the highest global weight of $18.45 \%$. This is understandable since time to repair has direct impact on revenue loss, interruption rate, and the user traffic frequency. Ease of providing alternative and user traffic frequency came next with close global weight values of $15.69 \%$ and $15.04 \%$, respectively. Both sub-attributes are seen as interrelated, since a decent alternative ensures customers are minimally affected by the service interruption. Revenue loss has a global weight of $14.96 \%$, based on experts' feedback; operational costs are usually used to cover moderate to low financial impacts of failure, and this explains the somehow moderate global weight of the revenue loss. Replacement/repair cost and service continuation are next, with close global weights, followed by interruption rate having the least weight of $10.22 \%$.

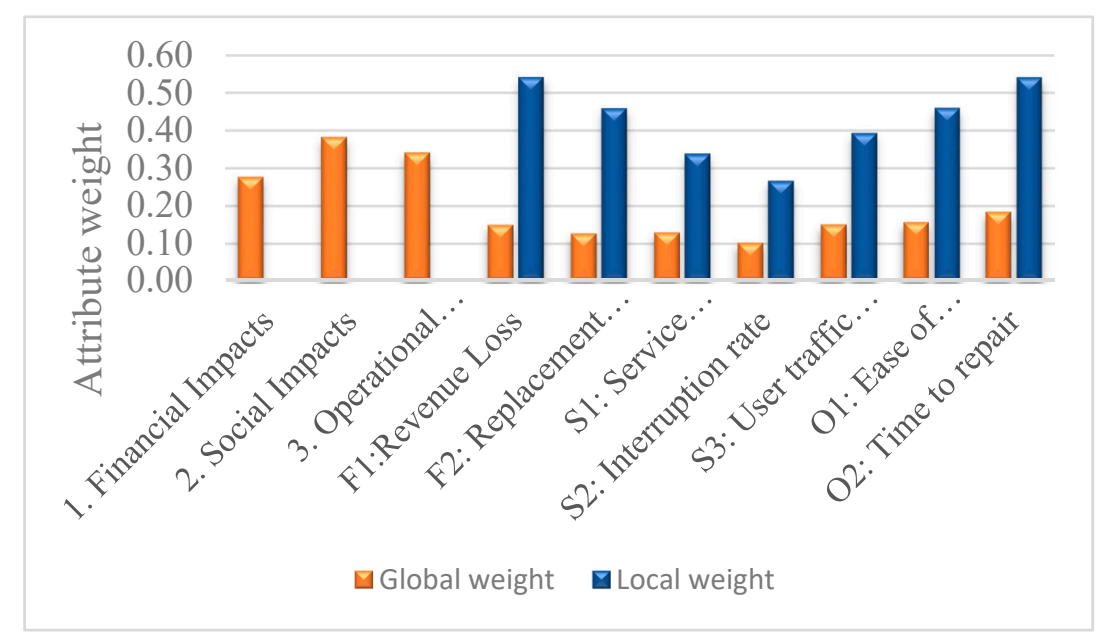

Figure 4. Failure impacts Local and Global Weights Plot.

\subsubsection{Compute the Severity Scores $\left(\mathrm{Ss}_{\mathrm{i}}\right)$}

Scores for failure impacts criteria are obtained using actual metro statistics available online, literature review, and inspection reports. Due to the high variability in the selected attributes nature, all scores were individually normalized based on the highest score provided per network. This ensures the proportionality of the failure impacts calculations are specific to the studied segment in our case study. Table 3 identifies each failure impact, the attributes considered in the analysis and a detailed description of each attribute. The score of each attribute is normalized based upon the network under study and the maximum and minimum score thresholds identified. 
Table 3. Failure impacts Definition and Scales.

\begin{tabular}{|c|c|c|c|c|}
\hline \multirow{2}{*}{ Failure Impact } & \multirow{2}{*}{ Attribute } & \multirow{2}{*}{ Definition } & \multicolumn{2}{|c|}{ Score } \\
\hline & & & Maximum & Minimum \\
\hline \multirow[b]{2}{*}{ Financial } & Replacement/repair cost & $\begin{array}{l}\text { Direct cost for replacement/repair of } \\
\text { the failed component }\end{array}$ & $\begin{array}{l}\text { Replacement } \\
\text { cost/element }\end{array}$ & $\begin{array}{c}\text { Repair } \\
\text { cost/element }\end{array}$ \\
\hline & Loss of revenue & $\begin{array}{l}\text { Profit loss due to service interruption, } \\
\text { factor of user traffic frequency, time to } \\
\text { repair and fare }\end{array}$ & $100 \%$ & $0 \%$ \\
\hline \multirow[t]{2}{*}{ Operational } & $\begin{array}{l}\text { Ease of providing } \\
\text { alternative }\end{array}$ & $\begin{array}{c}\text { Measured by the decision maker } \\
\text { based on the available bus stations } \\
\text { per area }\end{array}$ & \multicolumn{2}{|c|}{$\begin{array}{l}\text { Normalized based on maximum and } \\
\text { minimum number of bus } \\
\text { stops/station/network }\end{array}$} \\
\hline & Time to repair & $\begin{array}{l}\text { Required time to return the failed } \\
\text { component to a full functioning state }\end{array}$ & 365 days & 0 days \\
\hline \multirow{3}{*}{ Social } & User Traffic Frequency & $\begin{array}{c}\text { The number of users accessing the } \\
\text { station and affected by the service } \\
\text { interruption }\end{array}$ & \multicolumn{2}{|c|}{$\begin{array}{l}\text { Normalized based on maximum } \\
\text { ridership per network }\end{array}$} \\
\hline & Interruption Rate & $\begin{array}{l}\text { Defined by the decision maker as the } \\
\text { maximum allowable number of } \\
\text { interruptions per year }\end{array}$ & 6 & 0 \\
\hline & Service Continuation & $\begin{array}{l}\text { Estimated based on element } \\
\text { configuration and decision maker }\end{array}$ & $\begin{array}{l}\text { Full interruption } \\
\quad=100 \%\end{array}$ & $\begin{array}{c}\text { No interruption } \\
=0 \%\end{array}$ \\
\hline
\end{tabular}

The maximum allowable number of interruptions per year is averaged from experts' feedback in the questionnaire. Maximum time to repair is assumed to be 365 days, equivalent to one year, since the model analysis is done on an annual basis. User traffic frequencies for different stations are available online through reports and data published by the Subway transportation agency.

The replacement/repair cost were calculated using five generic Maintenance and Rehabilitation $(M \& R)$ treatment levels are based upon data from inspection reports, actual current network data, and literature review. [24] derived cost elements based upon different documents provided by transportation agencies and prepared by engineering firms and used them as guidelines to generate different treatment actions and the associated cost. Each treatment action is associated by an expected cost in $\$ / \mathrm{m}^{2}$ and an expected level of improvement. Table 4 presents five generic M\&R actions used in the analysis and their associated descriptions. Each $M \& R$ action data is used to input the failure impacts module scores, where applicable.

Table 4. M\&R Treatments and their Effects.

\begin{tabular}{cccc}
\hline Action & Description & \% Improvement & Expected Cost $\mathbf{\$} / \mathbf{m}^{\mathbf{2}}$ \\
\hline 1 & Do nothing & 0 & 0 \\
2 & Preventive Maintenance & $15 \%$ & 12,000 \\
3 & Minor Rehabilitation & $40 \%$ & 200,000 \\
4 & Major Rehabilitation & $65 \%$ & 225,000 \\
5 & Element Replacement & $100 \%$ & 500,000 \\
\hline
\end{tabular}

The module was applied to a case study of a subway network in Canada. The network details are kept confidential. The network is composed of four lines and more than 60 stations; five stations were selected to analyse using the model presented in [6]. Based on the probability of failure calculations, two stations were selected for further analysis: STA 4 and STA 6. STA 6 is currently under renovation; the actual renovation plan was considered in the model calculations. The station will be repaired during weekends only to minimize the service interruptions during which shuttle busses will be provided. The renovations were done over a time span of 25 weekends. Therefore, the interruption time is computed as $25 \times 2=50$ days. The service continuation is the percentage of days per week during which the service is unavailable; for this case, the service will be disrupted for 2 days each week, and a percentage of $2 / 7=0.285$ is used. The degree of interruption refers to the nature of interruptions requiring total, partial, or no station closure at all. STA 4 calculations are similar to that of STA6, 
where the interruptions were considered in weekends only. Since STA4 had a higher probability of failure, it was assumed the time to repair will be longer with a value proportional to the difference in probabilituy of failure values calculated. The fourth action of Major Rehabilitation was used as the scores input for STA4 and STA6 in the failure impacts module calculations.

User traffic frequency for all stations was obtained from online data available and normalized based upon the total ridership of the network under study. Calculations for computing failure impacts criteria scores and normalizing them is presented in Table 5 for financial impacts of failure. The actual value for revenue loss per station and the expected repair cost are shown. Normalized values for each of the financil impacts sub-attributes are also presented. Calculations are done using MS Excel ${ }^{\circledR}$ workbook where the entire framework calulations is located.

Table 5. Financial Impacts Scores.

\begin{tabular}{lccccc}
\hline \multirow{2}{*}{ Station } & \multirow{2}{*}{ System } & \multicolumn{4}{c}{ 1. Financial Impacts } \\
\cline { 3 - 6 } & & \multicolumn{2}{c}{ F1:Revenue Loss } & \multicolumn{2}{c}{ F2: Repair Cost } \\
\hline \multirow{2}{*}{ STA 4} & Station & 583,779 & 0.178 & 225,000 & 0.479 \\
\hline STA 6 & Station & 526,706 & 0.137 & 225,000 & 0.479 \\
\hline
\end{tabular}

Scores for social impacts of failure are presented in Table 6. For each station, the service continuation value is assigned based upon the M\&R scenario selected.

Table 6. Social Impacts Scores.

\begin{tabular}{|c|c|c|c|c|c|}
\hline \multirow{3}{*}{ Station } & \multirow{3}{*}{ System } & \multicolumn{4}{|c|}{ 2. Social Impacts } \\
\hline & & \multirow{2}{*}{ S1: Service Cont. } & \multirow{2}{*}{ S2: Interruption Rate } & \multicolumn{2}{|c|}{ S3: User Traffic Frequency } \\
\hline & & & & Actual Value & Normalized \\
\hline STA4 & Station & 0.285 & 1 & $1,092,714$ & 0.051 \\
\hline STA6 & Station & 0.285 & 1 & $1,281,651$ & 0.06 \\
\hline
\end{tabular}

In our case study segment, STA4 and STA6 required rehabilitation. Since STA6 is currently under rehabilitation, the actual rehabilitation value was used. STA6 is undergoing rehabilitation actions only on weekends to minimize the service disruption. Consequently, time to repair is calculated only on weekends for every given week, giving an overall service continuation percentage of 2/7 $=0.285$. While the rehabilitation actions were performed, a whole service disruption is expected and the entire station is closed, thus the interruption rate is total (1.0) for weekend rehabilitation activities. Operational impacts of failure scores are presented in Table 7.

Table 7. Operational Impacts Scores.

\begin{tabular}{cccccc}
\hline \multirow{2}{*}{ Station } & \multirow{2}{*}{ System } & \multicolumn{4}{c}{ 3. Operational Impacts } \\
\cline { 3 - 5 } & & Octual Value & Normalized & $\begin{array}{c}\text { O2: Time to Repair (Days) } \\
\text { Actual Value }\end{array}$ & Normalized \\
\hline STA 4 & Station & 4.000 & 0.444 & 65.000 & 0.178 \\
STA 6 & Station & 1.000 & 0.111 & 50.000 & 0.137 \\
\hline
\end{tabular}

Ease of providing alternative is calculated based upon the number of bus stops surrounding the metro station and normalized based upon the maximum number of stops available per station per study segment. Time to repair is the actual time required to return the failed component to a full functioning state. Time to repair of STA4 and STA6 are assumed proportional to their PoF values. 


\subsubsection{Compute Total Failure Impacts Score $\left(\mathrm{CF}_{\mathrm{i}}\right)$ per Element}

This is the last step in the failure impacts module. Failure impact score per element is calculated as the weighted product of each attribute using the weights and scores calculated in the previous steps. Table 8 presents the normalized scores of the different failure impacts attributes along with their global weights. The computed overall failure impacts score per element is also presented in the last column. The highest impact values are for stations (STA4) and (STA6), in which a high PoF value have been recorded, and thus, an M\&R action is triggered. From Table 8, it can be seen that failure impact values are equal for all systems in a given station building when no high PoF values are recorded. A high PoF value triggers an $M \& R$ action and thus an increased failure impact value for only the system with the failed component and not for the entire system. For STA4, a Failure Impact of 0.337 is obtained which confirms to the rehabilitation action done, whereas STA6 had a lower failure impact index of 0.272. The failure impact module values were revised and approved by experts.

Table 8. Failure impacts Module Calculations.

\begin{tabular}{cccccccccc}
\hline Segment & System & F1 & F2 & S1 & S2 & S3 & O1 & O2 & CoF \\
\hline \multirow{2}{*}{ Attribute Weight } & 0.149 & 0.127 & 0.13 & 0.102 & 0.15 & 0.157 & 0.185 & \\
\hline \multirow{2}{*}{ STB 4 } & Station & 0.178 & 0.479 & 0.285 & 1 & & & 0.178 & 0.337 \\
& Tunnel & 0 & 0 & 0 & 0 & 0.051 & 0.444 & 0 & 0.077 \\
& Aux & 0 & 0 & 0 & 0 & & & 0 & 0.077 \\
\hline \multirow{2}{*}{ STB6 } & Station & 0.137 & 0.479 & 0.285 & 1 & & & 0.137 & 0.272 \\
& Tunnel & 0 & 0 & 0 & 0 & 0.06 & 0.111 & 0 & 0.026 \\
& Aux & 0 & 0 & 0 & 0 & & & 0 & 0.026 \\
\hline
\end{tabular}

\subsection{Station Criticality Module}

Stations with similar failure impacts may still show different criticality levels with respect to the station size, location, and intensity of passengers, number of floors, and number of lines passing through the same station. Stations may have similar failure impacts, however, based on the station distinct characteristics with respect to the subway system being studied, stations can be prioritized for rehabilitation. Consequently, a criticality index is introduced to account for the factors affecting ranking stations for rehabilitations, which cannot be counted towards consequences of failure. When assessing a subway network, other factors exist which should be considered when ranking stations but cannot be counted towards impacts of failure. For instance, the number of lines connected in a station affects a station's ranking for rehabilitation but cannot be included as an impact of failure. Since lines are connected on different floors, the failure of a component on one floor should not affect other floors, unless the failed component is an interconnected element, which means it should be counted against the failure impacts measurements. The component location was studied and considered in the probability of failure estimation through utilizing the parallel-series network modeling technique to compute the probability of failure values for components and stations. Thus, the location of the component is addressed in a proper manner; however, the state of the station, being a connecting station or not, should still be addressed as a factor affecting the risk of failure of a station and its rehabilitation status.

The concept of criticality is introduced in this research as the criticality index. The subway breakdown hierarchy illustrated in Figure 5 is utilized in the criticality module development. Each level of the breakdown structure was studied to select the most suitable component for using in the criticality module implementation. The component is selected such that its criticality level would be dominant and diverse enough to prevail over the remaining network elements. Consequently, subway stations are selected to be the focus of the criticality analysis. Systems and subsystems share the same major important role of delivering the service; however, their criticality is derived from their respective locations in stations that vary in criticality according to factors and attributes that will be identified later. From this discussion, the concept of criticality propagation is introduced; the criticality level propagates 
upwards and downwards in a hierarchy of a subway network such that the systems and subsystems acquire the same criticality level as the stations in which they operate. Equally, a line criticality is computed as the weighted summation of criticality indices for the total number of stations existing on this line. For interconnecting systems such as tunnels and auxiliary structures, the criticality level is computed as the higher index of the two corresponding stations through which this system connects.

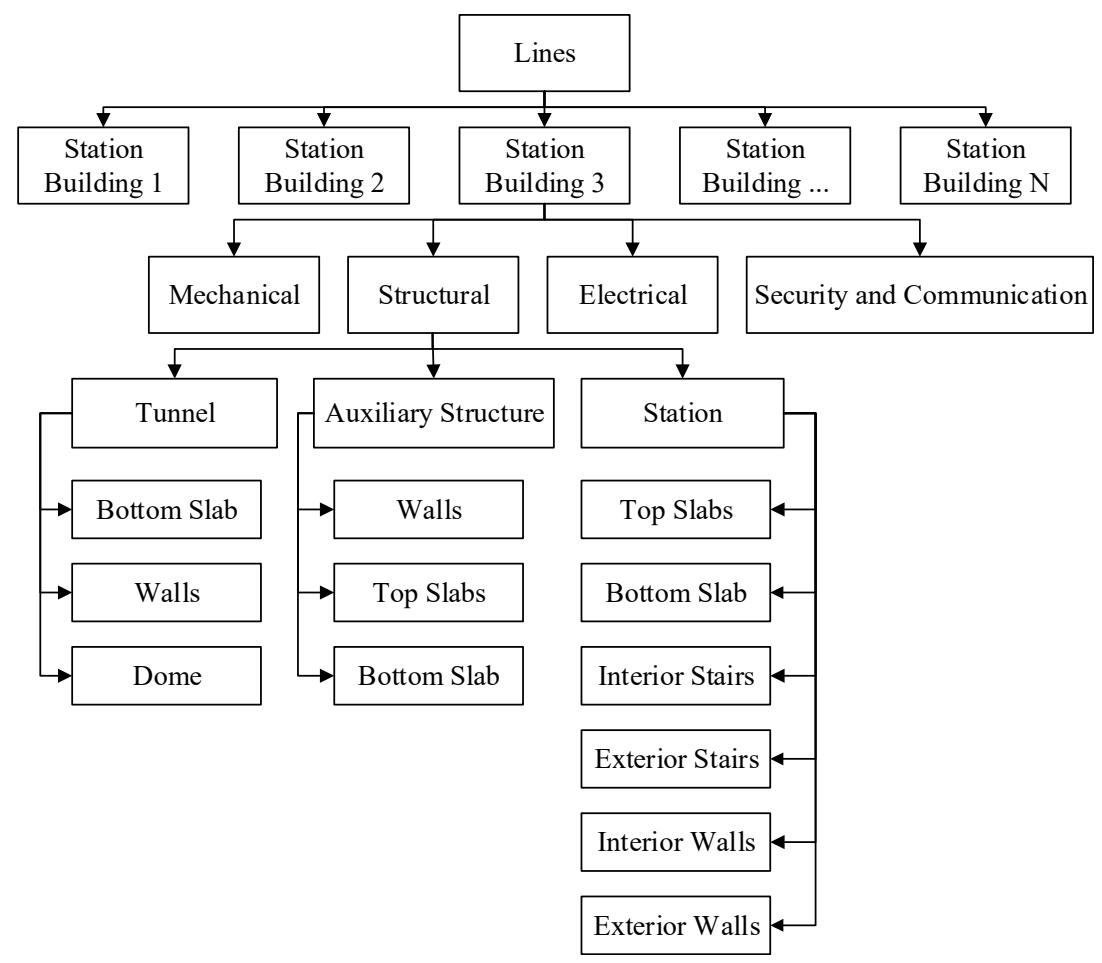

Figure 5. Proposed Subway Network Hierarchy [6].

The station criticality is a complex decision based on different attributes such as number of lines and levels in a station, station use, whether end or intermodal, and station location in proximity to all types of attractions. The criticality model framework is outlined in in Figure 6. Criticality of a subway station is identified by three main attributes and seven sub-attributes. The main criticality attributes are station characteristics, station location, and station nature of use.

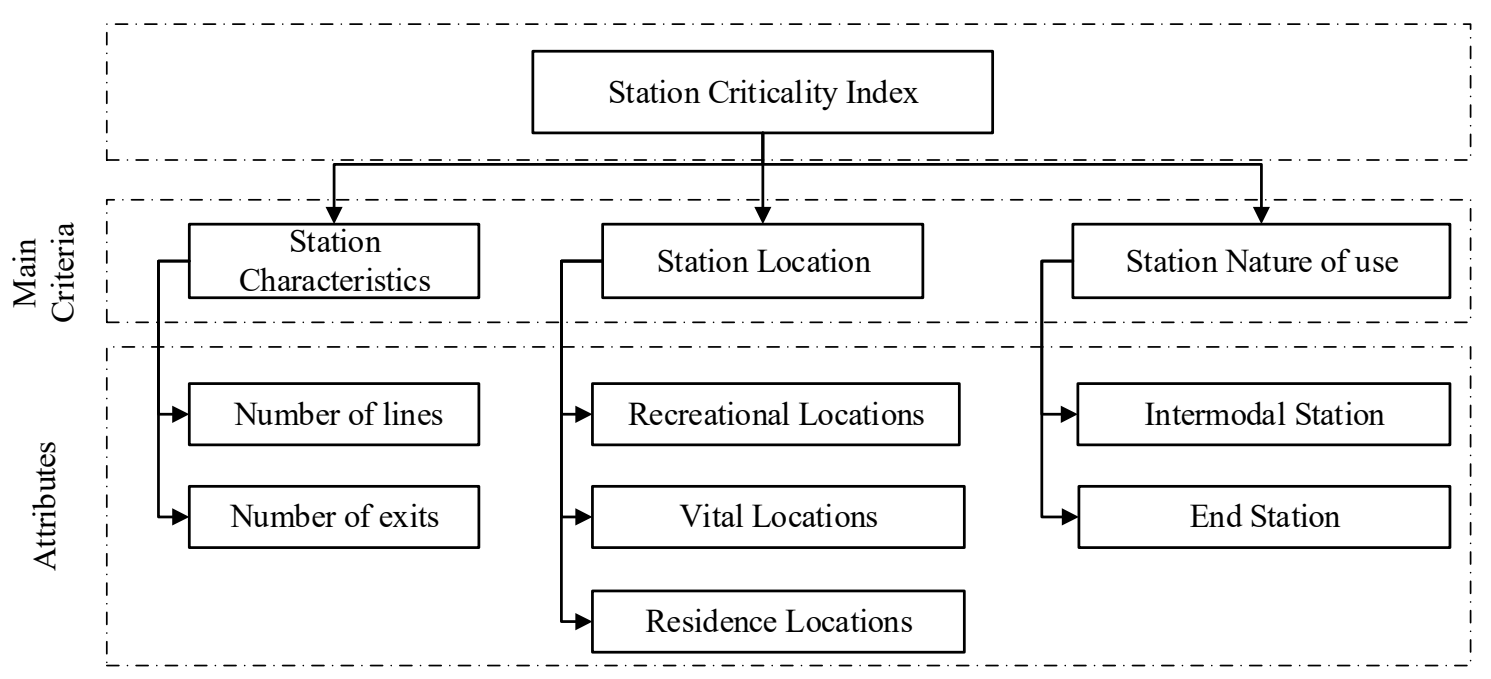

Figure 6. Criticality Module Attributes [25]. 
Station characteristics is defined in terms of number of lines and number of exits per station. Station location is considered to account for increased stations' criticality due to their proximity to important location, where the service is more required and the frequency of passengers is higher (e.g., hospitals, recreational areas, and universities). A binary value is assigned per station per location; in addition, a combined location option is permitted, and hence, a station can have value in all location attributes. Station nature of use account for station importance derived from its function as an end station or an intermodal station. The attributes and sub-attributes considered in the criticality index model are summarized in Table 9. The attribute scores are computed based upon the network under examination and individual station information. The scores are obtained as shown in Table 10.

Table 9. Subway Systems Criticality Attributes [25].

\begin{tabular}{ccc}
\hline Factor & Attributes & Description \\
\hline Station Size & $\begin{array}{c}\text { Number of lines } \\
\text { Number of exits }\end{array}$ & $\begin{array}{c}\text { Station size reflected as number of lines and number of exits } \\
\text { composing the station }\end{array}$ \\
\hline Station Location & $\begin{array}{c}\text { Recreational } \\
\text { Vitalities } \\
\text { Residence }\end{array}$ & $\begin{array}{c}\text { Station criticality based on its proximity to important locations } \\
\text { where higher passenger frequency is expected }\end{array}$ \\
\hline Station Nature of Use & $\begin{array}{c}\text { Intermodal Station } \\
\text { End station }\end{array}$ & $\begin{array}{c}\text { Station criticality derived from its nature as an intermodal station } \\
\text { Station criticality derived from its nature as an end station }\end{array}$ \\
\hline
\end{tabular}

Table 10. Criticality Attributes Definition and Scores [25].

\begin{tabular}{|c|c|c|c|}
\hline Factors & Attribute & Definition & Score \\
\hline \multirow{2}{*}{ Station Size } & \#exits & $\begin{array}{l}\text { The increased number of exits } \\
\text { reflects an increase in passenger } \\
\text { capacity }\end{array}$ & $\begin{array}{l}\text { Based on the maximum number of } \\
\text { exits as defined by user }\end{array}$ \\
\hline & \# lines & $\begin{array}{c}\text { The increased number of lines is } \\
\text { proportional to an increased } \\
\text { passenger capacity }\end{array}$ & $\begin{array}{l}\text { Based on the maximum number of } \\
\text { lines as defined by user }\end{array}$ \\
\hline \multirow{2}{*}{ Station Nature of Used } & Intermodal & $\begin{array}{l}\text { Intermodal stations pose a greater } \\
\text { importance since a higher } \\
\text { passenger frequency is expected. }\end{array}$ & $\begin{array}{l}\text { Computed as binary value, (1) for } \\
\text { an intermodal station and ( } 0) \text { if else }\end{array}$ \\
\hline & End station & $\begin{array}{l}\text { End stations pose a greater } \\
\text { importance since a higher } \\
\text { passenger frequency is expected. }\end{array}$ & $\begin{array}{l}\text { Computed as binary value, (1) for } \\
\text { an end station and (0) if else }\end{array}$ \\
\hline Station Location & $\begin{array}{l}\text { Recreational } \\
\text { Residence } \\
\text { Vitalities }\end{array}$ & $\begin{array}{l}\text { Stations pose higher criticality due } \\
\text { to their proximity to high } \\
\text { passenger frequency locations. }\end{array}$ & $\begin{array}{l}\text { Computed as binary value, }(1) \text { for } \\
\text { stations located in a high capacity } \\
\text { location and, (0) if else }\end{array}$ \\
\hline
\end{tabular}

From the definition of criticality attributes, inner and outer dependency occur between attributes analogous to those in the failure impacts module. Consequently, FANP was selected to assess criticality attributes, and a weight component is introduced in the criticality index equation to accommodate the subjective variability in the attributes weight. The score of each attribute is factor-dependent; it can be seen as a scale from less to more critical.

The criticality index model is summarized in the following steps;

1. Identify criticality attributes using literature review and experts' opinions;

2. Estimate criticality attributes weights $\left(C_{R} W_{i}\right)$ using pairwise comparison and FANP with application to FPP;

3. Perform FPP on each comparison matrix individually to derive sets of local priorities;

4. Calculate the weights using the FPP method according to Equation (5). It is required to derive crisp priority vector $w=\left(w_{1}, w_{2} \ldots w_{n}\right)^{T}$, such that the priority ratios $w_{i} / w_{j}$ are approximately within the scopes of the initial fuzzy linguistic judgments provided: 


$$
\begin{array}{r}
\left(m_{i j}-L_{i j}\right) \lambda w_{j}-W_{i}+L_{i j} W_{j} \leq 0 \\
\left(u_{i j}-m_{i j}\right) \lambda w_{j}+W_{i}-u_{i j} W_{j} \leq 0 \\
\mathrm{I}=1,2,3 \ldots \mathrm{n}-1, \quad \mathrm{j}=2,3 \ldots \mathrm{n}, \quad \mathrm{j}>\mathrm{i}
\end{array}
$$

where; $L_{i j}, m_{i j}, u_{i j}$ Lower, medium, and, upper bounds of triangular judgments, respectively;

5. Using expert opinion, station configuration and historical data, compute criticality scores $\left(C_{R} S i\right)$;

6. Compute the total Criticality Index per station $\left(C_{R}\right)$ using Equation (6):

$$
C_{R}=\sum_{i=1}^{n} C_{R} W_{i} * C_{R} S_{i}
$$

Among the selected attributes contributing to an increased station criticality, the station location is the most diverse. Criticality index measures the respective station importance based on a number of attributes including the station location in proximity to different attractions. Accordingly, the subway map was studied in depth. All possible points of interest accessible by a subway station or a bus from a subway station were identified and grouped by their relevance to three groups of locations. A station location is either in proximity to vitalities, recreational areas, or residence areas.

Table 11 lists the full description of existing points of interest in the case study subway clustered by their attraction type and grouped based on their relevance into three main groups.

Table 11. Attractions Definition by Group.

\begin{tabular}{ccc}
\hline Attraction Type & Points of Interest & Grouping \\
\hline Touristic Attractions & Museums, Theatres, Touristic Centers, Playgrounds, Historical & \\
Sports & Sites, and, Shopping Centers & Recreational \\
Culture & Amphitheaters, Gymnasiums, Stadium, and, Clubs & \\
Transportation & China Towns, Cinemas, Libraries, Cemetery & \\
Businesses & Central Bus Stations, Inter-city Rail Stations & \\
Worship Places & Chambers of Commerce, International District, Business District & \\
Educational & Churches, Mosques, Temples, Cathedral, Oratory & Sital Locations \\
Governmental & Schools, Universities, Educational Institutions & City Hall, Court \\
Health Care & Hospitals, Health Clinics, Health Institutes & Residence \\
Residence & High, Medium, or Low Residence Regions &
\end{tabular}

The criticality module phases are similar to those of the failure impacts module. First, local, and global weights are obtained using input from questionnaires and analyzed using FANP. Second, scores for different attributes are calculated and normalized based on the maximum and minimum values existent in the network understudy, where applicable. Last, scores and weights are combined to compute the final criticality index per station. In the criticality index module, normalization per score is only applicable in two attributes, number of exits and number of levels. The maximum number of exits considered is equal to the maximum number of exits in a station on the selected network for study. In our case, this number is equivalent to nine exits as concluded from the structural drawings of the stations. Maximum number of levels is calculated likewise, based on the maximum number in the network under study. The criticality index module operates on the stations system level. 


\subsubsection{Calculate Criticality Index Weights $\left(\mathrm{C}_{\mathrm{R}} \mathrm{W}_{\mathrm{i}}\right)$}

The third section of the questionnaire presents questions for rating criticality attributes with respect to their importance. Pairwise comparison matrices from the questionnaires are processed in MATLAB ${ }^{\circledR}$ to obtain local and global weights for attributes using FANP with application to FPP. The FANP MATLAB ${ }^{\circledR}$ code was used for the criticality index calculations following the same steps listed earlier. Local and global attributes weights are presented in Table 12. The three main criteria comprising the model had close weight values ranging from $31.82 \%$ to a maximum of $35 \%$ for station location. Attribute scores, on the other hand, show great variability in terms of global weight as shown in Figures 7 and 8. An intermodal station has the highest global weight of $24.37 \%$. This is expected since an intermodal station presents an intersecting number of lines and/or transportation modes which implies higher traffic frequency and consequently higher station importance.

Table 12. Criticality Attributes Weights Obtained Using FANP.

\begin{tabular}{ccccc}
\hline Main Criteria & Global Weight & Attributes & Global Weight & Local Weight \\
\hline \multirow{2}{*}{ Station Characteristics (C) } & \multirow{2}{*}{$31.82 \%$} & C1: Number of exits & $15.81 \%$ & $49.68 \%$ \\
& & C2: Number of Levels & $16.01 \%$ & $50.31 \%$ \\
\hline \multirow{2}{*}{ Station nature of use (N) } & \multirow{2}{*}{$33.13 \%$} & N1: End Station & $10.67 \%$ & $30.45 \%$ \\
& \multirow{2}{*}{$35.04 \%$} & N2: Intermodal Station & $24.37 \%$ & $69.55 \%$ \\
\hline \multirow{2}{*}{ Station Location (L) } & L1: Recreational & $06.29 \%$ & $18.99 \%$ \\
& L2: Residence & $09.42 \%$ & $28.45 \%$ \\
\hline
\end{tabular}

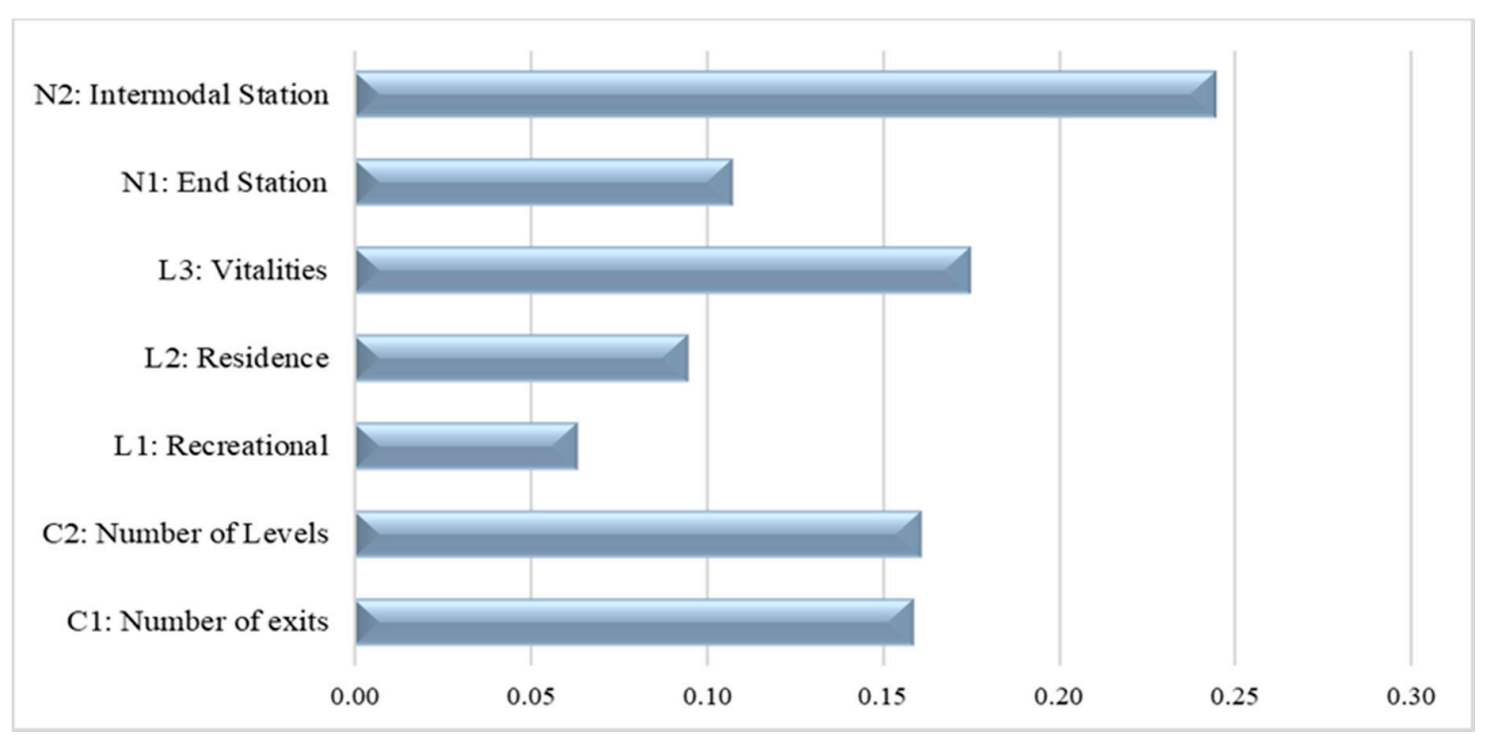

Figure 7. Criticality Index Attributes Global Weights. 


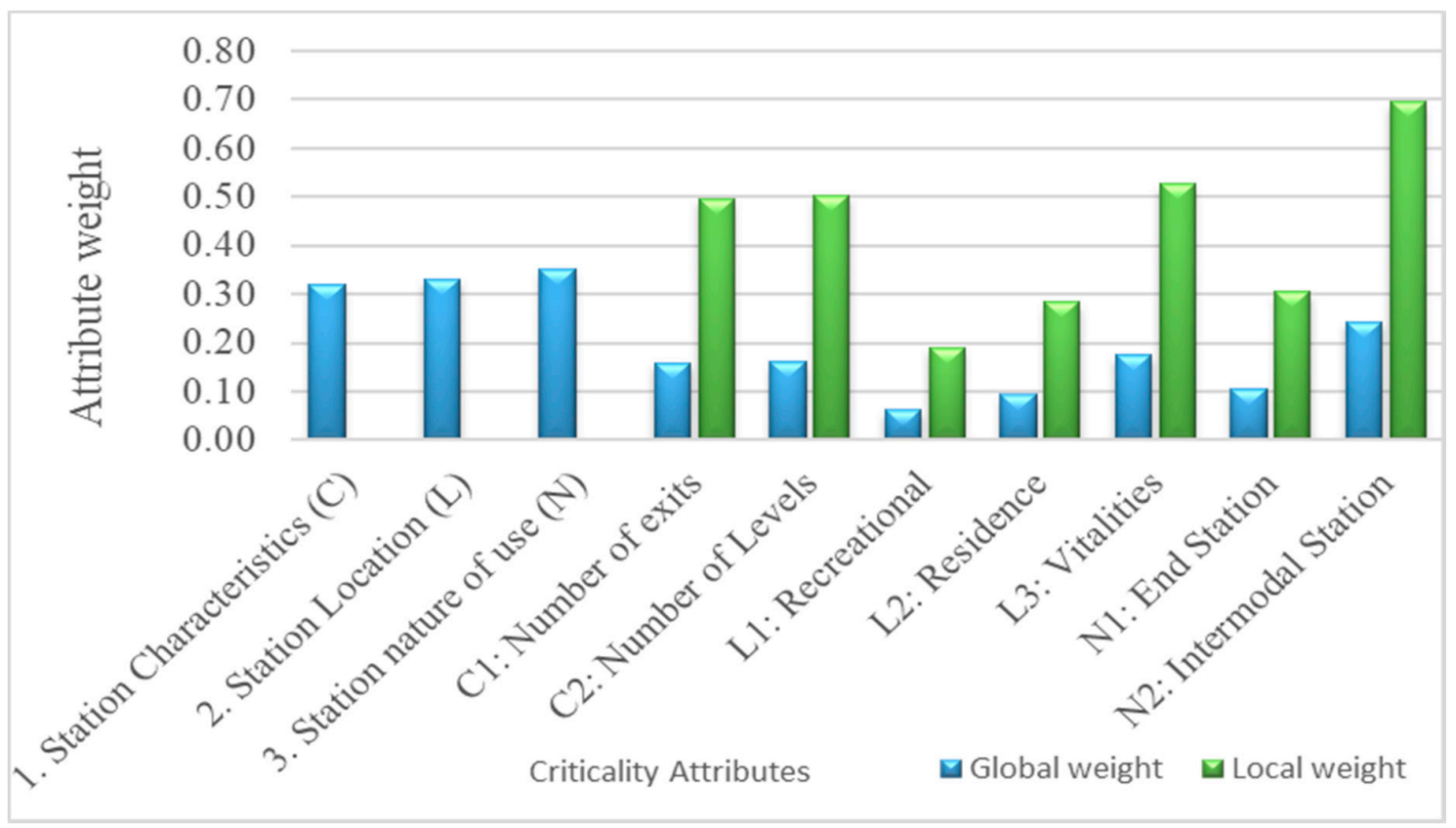

Figure 8. Criticality Attributes Local and Global Weights Plot.

\subsubsection{Model Testing}

The Criticality Index module was tested similar to the failure impacts module. The local and global weights presented in Table 12 and illustrated graphically in Figures 7 and 8 were revised in light of experts' feedback. The model was presented to and approved by the transportation authority personnel in charge of the network's risk assessment. They verified the model criteria were actually considered in their decision-making process and the output was legitimate and adequately conveys the network studied.

Stations located in a vital location had the second highest global weight of $17.41 \%$ followed by the number of levels $(16 \%)$ and number of lines $(15.8 \%)$ comprising a subway station. This analysis demonstrates the interdependency between the attributes; hence, none of the station criticality attributes can be measured independently. For instance, station nature of use affects number of exits and number of levels per station due to the expected rise in ridership. Moreover, the station ridership is directly proportional to the station location and proximity to different vital attractions. This highlights the power of the FANP as a calculation method where all the interdependencies are identified and included in the weight calculations. Based on experts' feedback, end stations have lower criticality at $(10.67 \%)$, whereas stations in residential and recreational locations have the least criticality weights, respectively.

\subsubsection{Criticality Scores $\left(\mathrm{C}_{\mathrm{R}} \mathrm{Si}\right)$}

Station criticality scores are calculated per station and then normalized for the segment under study. The number of exits in a station is representative of the original station importance and design ridership. It is normalized based on the maximum number of exits per station per network. The number of levels is computed for each station individually starting from the platform level to the station level; as identified in the inspection reports, normalization is based upon maximum number of levels per station per network. Station location is a binary value; a station acquires a score of 1 for every attribute it satisfies. Station nature of use attributes are calculated in a similar manner, where a station acquires a score of 1 if it is an intermodal or end station and 0 if otherwise. 


\subsubsection{The Total Criticality Index per Station $\left(C_{R}\right)$}

Criticality index for all stations in the subway network under study (68 stations) were calculated, whereas the index for the six stations in the segment under study were normalized based upon the maximum and minimum criticality index per network. Table 13 presents the criticality index calculations for the six stations in the studied segment. Scores are calculated for each station and then normalized with respect to the entire network as shown in the last column. Calculated criticality indices for different stations indicate STA 2 to be the most critical in the network. This is explained by the fact that STA 2 is the only station along the entire network to have three interconnecting lines, accordingly, having multiple levels and numerous exits. In addition, STA2 falls in proximity to the three location criteria of residence, vitalities, and recreational. This is followed by STA4 having a criticality index of 0.74 . STA4 is the deepest in the entire network having the maximum number of levels and high number of exits. This is reflected in the high criticality index of 0.74. STA3 and STA5 have an identical criticality index of 0.49 followed by STA1 with a criticality index of 0.37 , and lastly, STA6 with criticality index of 0.25 . The criticality index value was revised and approved by experts.

Table 13. Criticality Attributes Calculation.

\begin{tabular}{lccccccccc}
\hline & C1 & C2 & L1 & L2 & L3 & N1 & N2 & Score & Normalized Score \\
\hline STA1 & 0.05 & 0.10 & 0.06 & 0.09 & 0.00 & 0.00 & 0.00 & 5.91 & 0.37 \\
STA2 & 0.13 & 0.16 & 0.06 & 0.09 & 0.17 & 0.00 & 0.24 & 10.87 & 0.88 \\
STA3 & 0.03 & 0.10 & 0.06 & 0.09 & 0.17 & 0.00 & 0.00 & 7.05 & 0.49 \\
STA4 & 0.03 & 0.16 & 0.06 & 0.09 & 0.17 & 0.00 & 0.00 & 9.52 & 0.74 \\
STA5 & 0.03 & 0.13 & 0.06 & 0.09 & 0.00 & 0.00 & 0.00 & 7.11 & 0.49 \\
STA6 & 0.03 & 0.10 & 0.06 & 0.00 & 0.00 & 0.00 & 0.00 & 4.79 & 0.25 \\
\hline
\end{tabular}

\section{Conclusions}

Subway stations are assessed from a functional perspective on a systems level. Seven criteria were used to assess failure impacts along financial, social, and, operational perspectives. In addition, a criticality index is introduced to assess the functional importance a station plays in its location, considering ridership and relative station importance with respect to the line. Criticality is assessed using seven attributes along three main criteria. The failure impacts module revealed the social impacts had the highest relative weight of $38 \%$, followed by operational and financial impacts at $34 \%$ and $27.65 \%$, respectively. On the other hand, the failure impacts module indicated time to repair to have the highest global impact of $18.45 \%$, followed by ease of providing alternative and user traffic frequency at $15.69 \%$ and $15 \%$, respectively. Revenue loss at $14.96 \%$ was followed closely by service continuation $(12.95 \%)$ and replacement/repair cost $2.68 \%$, whereas the interruption rate came last at a global weight of $10.22 \%$. Assessing subway station criticality revealed station location to have the highest weight of $35 \%$ with stations in a vital location being the most important with local weight of $52.55 \%$, followed by stations in residence locations $28.45 \%$, and lastly, stations in recreational locations $19 \%$. Station nature of use as being end or intermodal was the second highest weight of 33\%, where intermodal station had higher local weight of $69.5 \%$, with respect to end stations with a weight of $30.5 \%$. Station characteristics came last, with an overall weight of $31.82 \%$; the two attributes within station characteristics came close with local weights of $49.7 \%$ and $50.3 \%$ for number of levels and number of exits, respectively. Given the fund scarcity problem existent in all public transportation authorities, subway stations have to compete for the available fund. This research provides decision makers with the necessary tools to make an informed decision to prioritize stations for available fund given the functional aspects of each station with respect to the expected failure impacts of the station and the criticality of the station with respect to the line(s) in which it operates. 
Author Contributions: Conceptualization, M.A.; methodology, M.A.; software, M.A.; validation, M.A.; formal analysis, M.A.; investigation, M.A.; resources, M.A. and T.Z.; data curation, M.A.; writing-original draft preparation, M.A.; writing-review and editing, M.A.; visualization, M.A.; supervision, T.Z.; funding acquisition, M.A. and T.Z. All authors have read and agreed to the published version of the manuscript.

Funding: This research was funded by Concordia University Special scholarship award.

Acknowledgments: The authors would like to acknowledge the support provided by the Transportation Agency in providing required inspection reports and valuable feedback.

Conflicts of Interest: The authors declare no conflict of interest.

\section{References}

1. The Canadian Infrastructure Report Card: Informing the Future (2019). 2019. Available online: http: //canadianinfrastructure.ca/downloads/canadian-infrastructure-report-card-2019.pdf (accessed on 15 July 2020).

2. International Organization for Standardization (ISO) 55000. Asset Management-Overview, Principles, and Terminology (ISO Standard 55000). 2016. Available online: https://www.iso.org/standard/55088.html (accessed on 12 July 2020).

3. Semaan, N.; Zayed, T. Subway Station Diagnosis Index Condition Assessment Model. J. Infrastruct. Syst. 2009, 15, 222-231. [CrossRef]

4. Deng, Y.; Li, Q.; Lu, Y. A research on subway physical vulnerability based on network theory and FMECA. Saf. Sci. 2015, 80, 127-134. [CrossRef]

5. Gkountis, I.; Zayed, T. Subway Infrastructure Condition Assessment. J. Constr. Eng. Manag. 2015, 141, 04015042. [CrossRef]

6. Abouhamad, M.; Zayed, T. Risk-Based Asset Management Framework for Subway Systems. J. Constr. Eng. Manag. 2019, 145, 04019071. [CrossRef]

7. Dawood, T.; Zhu, Z.; Zayed, T. Deterioration mapping in subway infrastructure using sensory data of GPR. Tunn. Undergr. Space Technol. 2020, 103, 103487. [CrossRef]

8. Water Research Center (WRC). Sewerage Rehabilitation Manual, 2nd ed.; Water Research Center/Water Authorities Association: Swindon, UK, 1986.

9. Hahn, M.A.; Palmer, R.N.; Merrill, M.S.; Lukas, A.B. Expert System for Prioritizing the Inspection of Sewers: Knowledge Base Formulation and Evaluation. J. Water Resour. Plan. Manag. 2002, 128, 121-129. [CrossRef]

10. Kleiner, Y.; Sadiq, R.; Rajani, B.B. Modeling failure risk in buried pipes using fuzzy Markov deterioration process. In Pipeline Engineering and Construction: What's on the Horizon? Amer Society of Civil Engineers: San Diego, CA, USA, 2004; pp. 1-12.

11. Baris, S. Infrastructure Management and Deterioration Risk Assessment of Wastewater Collection Systems. Ph.D. Thesis, University of Cincinnati, Cincinnati, OH, USA.

12. Fares, H.; Zayed, T. Hierarchical Fuzzy Expert System for Risk of Failure of Water Mains. J. Pipeline Syst. Eng. Pr. 2010, 1, 53-62. [CrossRef]

13. Martin, T.; Johnson, D.; Anschell, S. Using Historical Repair Data to Create Customized Predictive Failure Curves for Sewer Pipe Risk Modeling. In Proceedings of the LESAM 2007-2nd Leading Edge Conference on Strategic Asset Management, Lisbon, Portugal, 17-19 October 2007.

14. Carretero, J.; Perez, J.; Garcia-Carballeira, F.; Calderon, A.; Fernandez, J.; Garcia, J.; Lozano, A.; Cardona, L.; Cotaina, N.; Prete, P. Applying RCM in large scale systems: A case study with railway networks. Reliab. Eng. Syst. Saf. 2003, 82, 257-273. [CrossRef]

15. Gonzalez, J.; Romera, R.; Perez, J.C.; Perez, J. Optimal Railway Infrastructure Maintenance and Repair Policies to Manage Risk under Uncertainty with Adaptive Control. Madrid, E-Archivo, el Repositorio Institucional de la Universidad Carlos III. Available online: http://www.temoa.info/node/200579\T1\textgreater\{\} (accessed on 8 May 2012).

16. Leeman, B. Edmonton's Risk Based Infrastructure Management System. Available online: http://www.cnam.ca/uploads/Documents/Workshop/2010/presentations/CNAM10_Session_3_The_City_of_ Edmontons_Risk_Based_Infrastructure_Management_System_Leeman.pdf (accessed on 5 May 2012).

17. Promentilla, M.A.; Furuichi, T.; Ishii, K.; Tanikawa, N. A fuzzy analytic network process for multi-criteria evaluation of contaminated site remedial countermeasures. J. Environ. Manag. 2008, 88, 479-495. [CrossRef] [PubMed] 
18. Chu, A.T.W.; Kalaba, R.E.; Spingarn, K. A comparison of two methods for determining the weights of belonging to fuzzy sets. J. Optim. Theory Appl. 1979, 27, 531-538. [CrossRef]

19. Crawford, G.; Williams, C. A note on the analysis of subjective judgment matrices. J. Math. Psychol. 1985, 29, 387-405. [CrossRef]

20. Bryson, N. A goal programming method for generating priority vectors. J. Oper. Res. Soc. 1995, 46, 641-648. [CrossRef]

21. Mikhailov, L.; Singh, M. Fuzzy analytic network process and its application to the development of decision support systems. In Systems, Man, and Cybernetics, Part C: Applications and Reviews; IEEE: New York, NY, USA, 2003; Volume 33, pp. 33-41.

22. Mikhailov, L. Deriving priorities from fuzzy pairwise comparison judgements. Fuzzy Sets Syst. 2003, 134, 365-385. [CrossRef]

23. Saaty, T.L. Decision Making with Dependence and Feedback: The Analytic Network Process, 2nd ed.; RWS Publications: Pittsburgh, PA, USA, 2001.

24. Farran, M. Life cycle cost for rehabilitation of public infrastructures: Application to Montreal metro system. Master's Thesis, Concordia University, Montreal, QC, Canada, 2006.

25. Abouhamad, M.; Zayed, T. Criticality-Based Model for Rehabilitating Subway Stations. In Proceedings of the International Symposium on Automation and Robotics in Construction, Montreal, QC, Canada, 11-15 August 2013; IAARC Publications: Red Hook, NY, USA; Volume 30, pp. 1296-1304.

(C) 2020 by the authors. Licensee MDPI, Basel, Switzerland. This article is an open access article distributed under the terms and conditions of the Creative Commons Attribution (CC BY) license (http://creativecommons.org/licenses/by/4.0/). 